\title{
PECTORAL DEL TEMPLO MAYOR CON LA FIGURA DE UNA DEIDAD
}

NELLY GUtiéRREZ SOLANA

A Hasso von Winning

\section{Localización de la pieza y fechamiento}

Este pectoral formaba parte de la ofrenda colocada en la Cámara I (cista 5). Dicha Cámara I se encontró, en marzo de 1978, debajo de la escalera del Templo de Huitzilopochtli en la fachada oeste del recinto sagrado y al este del gran monolito de la Coyolxauhqui. Un dibujo del pectoral aparece en García Cook y Arana, 1978, pero está incorrecto. Matos publicó la foto y la descripción del mismo en 1990.

La ofrenda de la Cámara I resultó muy importante ya que incluía un monolito de piedra verde con la figura de una deidad identificada por Alfredo López Austin como Mayahuel, la diosa del pulque. ${ }^{1}$ En esta ofrenda se hallaron 152 elementos además de cuentas y otros objetos pequeños. Entre estos elementos destacan los siguientes: una docena de figurillas tipo Mezcala elaboradas en piedra verde, un disco de piedra verde, un pectoral de concha, varios grupos de caracoles con vestigios de pintura roja y amarilla, discos de obsidiana, etcétera. ${ }^{2}$

Para la elaboración del pectoral se empleó una piedra verde. Las técnicas usadas fueron el bajorrelieve y la incisión para algunos detalles. El labrado es de buena calidad y con todo cuidado se representaron los detalles de la pintura facial y el atavío. La obra mide $13 \mathrm{~cm}$ de largo máximo y $11 \mathrm{~cm}$ de ancho máximo y se encuentra en buen estado de conservación.

La pieza parece haber sido reusada. En un lado presenta el contorno de un rostro humano de perfil; pueden observarse la nariz, la boca y una orejera circular. Posteriormente se labró del otro lado una figura antropomorfa que es el tema de este estudio. Es probable que entonces se hicieran los agujeros para usarse como pectoral ya que por la posición de los mismos

${ }^{1}$ Alfredo López Austin, "Iconografía mexica. El Monolito Verde del Templo", Anales de Antropologia, núm. XVI (México, 1979), pp. 133-153.

2 Ángel García Cook y Raúl M. Arana, Rescate arqueológico del monolito Coyolxanhqui, México, Universidad Nacional Autónoma de México, 1978, pp. 58-64. 
el rostro de perfil quedaría boca abajo. La pieza se exhibe en el Museo del Templo Mayor y, por los estudios realizados por los arqueólogos, la ofrenda de la cual formaba parte pertenece a la época IV que corresponde al gobierno de Moctezuma I ${ }^{3}$ (1440 a 1468 o 1469, esta última fecha varía según las fuentes).

\section{Identificación de la figura}

La figura se encuentra en una extraña posición con el torso casi horizontal y con un pie en el aire. ${ }^{4}$ Se trata de un personaje masculino ya que usa máxtlatl. Pienso que se trata de la representación de un dios o de un personificador de un dios.

Los elementos más importantes para su identificación son los siguientes: el pelo con dos elementos al frente que se bifurcan y como tocado presenta un rosetón y dos tiras dispuestas hacia atrás; la pintura facial consiste de tres franjas, dos con triángulos además de una lisa, y un borde alrededor de la boca que pudiera indicar pintura; la nariguera en forma de flecha; el átlatl que lleva en una mano y el escudo con las flechas que porta en la otra, y por último el adorno de la parte posterior de la espalda en forma de un abanico del cual emerge un elemento cónico. No es común la cuerda llevada en la cintura y que probablemente sirva para detener al mäxtlatl.

Las otras partes de su atavío son comunes a la mayoría de las representaciones de los dioses: orejera, pulseras, collar de cuentas, pectoral, elementos anudados debajo de las rodillas y sandalias. Lleva además dos franjas colgantes detrás de la nuca y una tira muy larga que se desprende del tocado, cae a un lado de la cara y se continúa hasta casi llegar al límite del pectoral. Por último presenta una franja dispuesta diagonalmente, debajo del adorno posterior de la espalda. ${ }^{5}$

Es difícil identificar al dios del pectoral; sin embargo, analizaremos con cuidado sus rasgos para establecer de qué deidad se trata.

\footnotetext{
${ }^{3}$ Eduardo Matos, "Imperial Tenochtitlan", Mexico Splendors of Thirty Centuries, Nueva York, The Metropolitan Museum of Art, 1987, p. 41.

${ }^{4}$ En una posición similar se encuentra el dios solar representado en un disco perteneciente al Museum of the American Indian Heye Foundation y otras esculturas mexicas además de figuras dibujadas en los códices del altiplano. No es posible saber si dicha posición tenía un significado especial.

${ }^{5}$ Hay otro relieve hecho de concha o caracol con una figura muy semejante Lleva también un átlatl, el mismo tipo de tocado y el adorno con el elemento cónico. Se trata probablemente de la misma deidad y se encuentra en exhibición en el Museo del Templo Mayor. Hasta 1988 esta pieza no había sido publicada
} 
Varios elementos permiten considerar que este dios pertenece al complejo llamado por Nicholson "el complejo de Mixcóatl-Tlahuizcalpantecuhtli", complejo que incluye a las deidades que "simbolizan el tipo de vida de los chichimecas cazadores y recolectores" ${ }^{6}$ además este complejo está relacionado con la guerra.

Dentro del complejo de Mixcóatl-Tlahuizcalpantecuhtli hay varios dioses menores venerados por los pueblos de las chinampas de la cuenca de México. El dios del pectoral lleva varios elementos indicativos de dicho complejo: el átlatl del cazador, la nariguera propia de los grupos chichimecas y las flechas con el escudo asociados a la guerra. Muestra además el pelo formando dos rizos al frente tal como los lleva Mixcóatl en la página 41 del Códice Fejéruáry-Mayer. Podría pensarse, por lo tanto, que el dios del pectoral es Mixcóatl pero nuestro dios presenta asimismo un elemento que lo vincula a los dioses de la muerte, a saber, el adorno posterior de la espalda en forma de abanico con un elemento cónico. ${ }^{7}$ Dentro del complejo ya mencionado un dios que lleva este elemento Atlahua, ${ }^{8}$ por lo tanto, considero que el dios representado en el pectoral es Atlahua.

El complejo de Mixcóatl-Tlahuizcalpantecuhtli tenía asociaciones con Huitzilopochtli ${ }^{9}$ y con Tezcatlipoca. Por eso no debe extrañarnos que el tipo de rizos al frente del pelo sean similares a los que ostenta Huitzilopochtli en las láminas 31, 34 y 36 del Códice Borbónico y en el relieve labrado en la oquedad del cuauhxicalli del tigre. Las tres franjas del rostro de nuestro dios son semejantes a las que lleva Huitzilopochtli en la lámina 36 del Códice Borbónico y en el folio 261r del Códice Matritense del Real Palacio aunque las de Huitzilopochtli carecen de los elementos triangulares de la deidad aquí estudiada. Es frecuente que Tezcatlipoca tenga también tres franjas como pintura facial. En la misma lámina 36 del Códice Borbónico Huitzilopochtli muestra color rojo alrededor de la boca y el dios de nuestra pieza tiene una línea que pudiera indicar que llevaba pintada asimismo el área de la boca. En cuanto a la nariguera, en forma de flecha, del dios aquí estudiado podemos encontrarla en las figuras de Tezcatlipoca

\footnotetext{
${ }^{6}$ Henry B. Nicholson, "Religion in Pre-Hispanic Central Mexico", Handbook of Middle American Indians, vol. 10, Austin, University Press, 1971, p 426

${ }^{7}$ Dicho elemento lleva el nombre de cuexcochtechimalli ya que los dioses de la muerte lo llevan generalmente detrás de la nuca. Puede aparecer como parte del tocado y menos comúnmente en la parte superior de la espalda. No es frecuente que aparezca, como en nuestra figura, en la parte inferior de la misma En nuestro pectoral la posición del dios, con la cabeza echada hacia atrás, podría ser una explicación del porqué se representó tan abajo del cuerpo.

${ }^{8}$ Como puede verse en el folio 265r del Códice Matritense del Real Palacio.

${ }^{9}$ Nicholson, op cit., p. 426 .
} 
ilustradas en el Códice Magliabechi, páginas 33 y 37. Nuestro dios tiene, por lo tanto, elementos que lo vinculan tanto a Huitzilopochtli como a Tezcatlipoca. ${ }^{10}$

\section{El dios Atlahua en las fuentes}

Atlahua significa el Señor del Átlatl, el dueño del lanzadardos. ${ }^{11}$ Según nos dicen los informantes de Sahagún ${ }^{12}$ era junto con Amimitl, dios de los de Cuitláhuac y de los habitantes de las chinampas. Cuitláhuac [en la época actual Tláhuac], al igual que los otros pueblos chinampanecos (Xochimilco, Culhuacán y Mixquic), se encuentra situado en la parte sur de la cuenca de México. Tanto Atlahua como Amimitl eran dioses relacionados con la caza de animales acuáticos, una de las actividades económicas importantes de los habitantes de los lagos. En las fuentes se asocian estos dioses con ciertas enfermedades sobre todo con una tos crónica que inclusive llevaba a los enfermos a echar sangre por la boca. ${ }^{13}$

En el folio 265r del Códice Matritense del Real Palacio está ilustrado Atlahua con sus atavíos característicos. También se le representó en la sección de las fiestas concretamente en las ilustraciones del Títitl y Tóxcatl. En el Códice Florentino aparece Atlahua como un jefe danzando con una sonaja pero sin su atavío típico. ${ }^{14}$

Varios investigadores, como Garibay y más recientemente Brundage, consideran que Atlahua y Amimitl estaban relacionados estrechamente con Opochtli, dios de la pesca y de la cacería de animales acuáticos. Así el primer autor nos dice que estos tres no son más que una misma deidad con tres nombres diferentes. ${ }^{15}$ Brundage, por su parte, opina que Amimitl y Atlahua son deificaciones de las armas de Opochtli, Amimitl del arpón y Atlahua del átlatl. ${ }^{16}$ Seler nos dice que el atavio de Atlahua reúne atributos de

${ }^{10}$ Dudo que el dios de nuestro relieve pudiera ser Huitzilopochtli o Tezcatlipoca por el hecho de que estos dioses no suelen mostrar el cuexcotechimalli. No creo tampoco que sea un dios solar pues carece de los elementos que identifican a Tonatiuh como son el disco con los rayos solares y el tocado con la mariposa.

${ }^{11}$ Otra interpretación del nombre es "El dueño del agua"; sin embargo, Ángel María Garibay, Veinte himnos sacros de los nahuas, México, Universidad Nacional Autónoma de México, 1958, p. 213, considera que la traducción "El dueño del lanzadardos" es más apropiada

${ }^{12}$ Códice Matritense del Real Palacio, fol $36 \mathrm{r} \mathrm{y} \mathrm{v.}$

${ }_{13}^{13}$ Códice Matritense del Real Palacio, fol. $36 \mathrm{r} \mathrm{y} \mathrm{v.}$

${ }^{14}$ Apud, J. O. Arthur Anderson y Charles E. Dibble, Florentine Codex, 2a ed., Nuevo México, 1981, Libro 2, fig 66 antes de la página 103.

${ }^{15} \mathrm{Ibid}$. p. 213.

${ }^{16}$ Burr C. Brundage, El Quinto Sol. Dioses y mundo azteca, México, Edit. Diana, 1982, p. 183 
Huitzilopochtli y Painal, de los Chachalmeca y de Mixcóatl. ${ }^{17}$ A mi parecer la relación con Mixcóatl es más convincente que la relación con Opochtli.

Si Atlahua y Amimitl se derivaron de Mixcóatl (o de Opochtli) serían ejemplos de la multiplicación de dioses que Alfredo López Austin explica de la manera siguiente: al proceso de creciente complejidad política, en que numerosas pequeñas unidades se veían precisadas a relacionarse y diferenciarse entre sí, correspondería un aumento de dioses. ${ }^{18}$ Esto pudo haber sucedido antes de la llegada de las tribus a la cuenca de México o después.

La relación de Atlahua con los dioses llamados Chachalmeca es muy estrecha ya que tienen los siguientes elementos en común: el cuexcotechimalli, el bastón denominado tímetl (que como veremos es común que lo lleve Atlahua en el Códice Borbónico) y el escudo mitad rojo y mitad blanco (ychimal eztlapanqui). Los dioses Chachalmeca es posible que se hayan originado, según Seler, en la región junto a los volcanes. ${ }^{19} \mathrm{~A}$ los ayudantes de los sacerdotes encargados de los sacrificios se les llamaba asimismo Chachalmeca.

\section{Atlahua en los códices}

La ausencia de Atlahua en los códices del Grupo Borgia es una indicación de que 1) quizá sea un aspecto de Mixcóatl que no se había desarrollado cuando se elaboraron dichos códices; 2) que su culto fue traído por las tribus nahuatlacas que entraron a la cuenca de México más tardíamente, ${ }^{20}$ o 3) que se elaboraron en regiones donde este dios no era venerado. En la Historia de los mexicanos por sus pinturas al hablar de las tribus nahuatlacas migratorias se nos dice que salieron los de Cuitláhuac con su dios Amimitl el cual era una vara (es decir un dardo) de Mixcóatl. ${ }^{21}$ Podemos pensar que Atlahua era una deidad de esta misma tribu o de otras asimismo nahuatlacas.

\footnotetext{
${ }^{17}$ Eduard Seler, Ein Kapitel aus den Geschichtswerk des P. Sahagun, vol. 1, Cuaderno 4, 1890, p. 58. Painal es un aspecto de Huitzilopochtli.

${ }^{18}$ Alfredo López Austin, "Nota sobre la fusión y la fisión de los dioses en el panteón mexica", Anales de Antropología, vol. 1, núm. XX (México, 1983).

${ }^{19}$ Eduard Seler, Gesammelte Abhandlungan zur Amerikanischen Sprach-und Althterthumskinde, tomo II, Berlín, 1904, p 430

20 Aunque las fuentes como Chimalpahin se refieren a la llegada de los chichimecas a Cuitláhuac por 1162, no fue sino hasta 1230 que se entronizó Cohuatomatzin en Cuitláhuac, Códice Chimalpopoca, "Anales de Cuauhtitlán, y leyenda de los Soles", traducción de P.F. Velázquez, México, Universidad Nacional Autónoma de México, 1975, p. 17.

21 "Historia de los mexicanos por sus pinturas" en Teogonía e historia de los mexicanos, edición de Ángel Ma Garibay, Edit. Porrúa, México, 1965, pp. 40 y 41.
} 
Es de particular interés que Atlahua aparezca casi exclusivamente en el Códice Borbónico. Tanto Nicholson como Nowotny opinan que dicho códice puede provenir de algún pueblo de la parte sur de la cuenca del valle; el primero habla específicamente de Culhuacan o Itztapalapan ${ }^{22}$ mientras que el segundo opina que quizá provenga de algún pueblo de las chinampas. ${ }^{23}$ En dicho códice Atlahua aparece en las fiestas Tóxcatl, Tlaxochimaco y Títitl. Es importante considerar que en Tóxcatl y Títitl se veneraba especialmente a Tezcatlipoca y a Huitzilopochtli, y en Tóxcatl había una gran fiesta en Tlaxcala para honrar a Mixcóatl Camaxtli. Por lo tanto no es de extrañar que nuestro dios fuera venerado también en estas fiestas por los lazos que tenía con dichas deidades. En las ilustraciones de dicho códice Atlahua aparece con dos elementos que están ausentes en nuestro relieve: el cerco negro en torno de los ojos rodeado de pequeños círculos blancos ${ }^{24}$ y el objeto que lleva en una mano y al cual me referiré posteriormente. En la sección de las fiestas en el Códice Matritense del Real Palacio también se representó a Atlahua pero carece del antifaz que porta en el Códice Borbónico. ${ }^{25}$

El elemento que lleva en la mano consiste de un bastón de dos haces al cabo llamado tímetl. El color varía ya que en el Códice Borbónico está pintado un haz de verde y el otro de negro; en la sección de las fiestas, mencionada en el párrafo anterior, aparece en un caso con un haz en verde y el otro en blanco, y en el otro ejemplo con ambos en blanco. En el fol. $265 \mathrm{r}$ del Códice Matritense del Real Palacio un haz es rojo y el otro blanco y en la descripción de atavío del dios se habla de su bastón rojo. Al referirse a él, Seler nos dice que no tenemos mayor información del significado del objeto ni tampoco de qué significaba que un dios lo portara ${ }^{26}$ Los dos haces pudieran ser hojas alargadas y terminadas en punta de alguna planta, lo cual sería congruente con el color verde que suelen presentar. En el canto a Atlahua

${ }^{22}$ Henry B. Nicholson, "The provenience of the Codex Borbonicus: an hypothesis, Smoke and Mist, England, BAR Internacional Series 402 (1), 1988b, p. 78

${ }^{23}$ Apud, Nicholson, Ibid.

${ }^{24}$ En la representación de Mixcóatl de la página 26 del Códice Fejérváry Mayer el dios carece del antifaz negro que es común que muestre en los códices, lo cual sería un caso semejante al de nuestro relieve.

${ }_{25}$ Dicho antifaz lleva el nombre de mixtetlilcomolo, mixcitlalhuiticac, que León Portilla traduce como "círculos negros alrededor de los ojos, con estrellas alrededor de los ojos", Miguel León Portilla, Ritos, sacerdotes y atavios de los dioses, México, Universidad Nacional Autónoma de México, 1958, p. 141, y que Seler interpreta como "una pintura facial que representa al oscuro cielo nocturno, el cielo estrellado", Eduard Seler, Comentarios al Códice Borgia, México, Fondo de Cultura Económica, 1963, tomo I, p. 188.

${ }^{26}$ Eduard Seler, Religious Songs of the Ancient Mexicans, traducción mecanuscrita al inglés, vol. 2, parte 4, s.f., p. 84 y 85 . 
hay una referencia a cañas, aca xelivi, pero no parece tratarse de cañas en los dibujos mencionados.

No debe extrañarnos que Atlahua no aparezca en el arte tenochca ni tampoco en los otros códices del altiplano central con excepción del Códice Borbónico como ya vimos. Esto se explica porque Atlahua no era un dios de los mexicas sino de los pueblos chinampanecos como lo establecen las fuentes. Es necesario mencionar aquí que sí aparece en los Primeros Memoriales, es decir, en la parte de los Códices Matritenses que fue elaborada en Tepepulco, comunidad perteneciente a la provincia de Acolhuan. Dicha provincia, cuya capital era Texcoco, ocupaba la parte oriental de la cuenca de México. Al respecto tiene importancia lo que nos dice Henry $B$. Nicholson: "Los Primeros Memoriales incluyen varias deidades menores como los Chachalmeca, Amimitl, Atlahua, Chalmecacihuatl lo cual apunta particularmente a la parte sur de la cuenca de México, al área Chalco-chinampaneca con la cual la región norteña de Acolhuacan tenía tradicionalmente nexos históricos estrechos." "27

La aseveración anterior nos lleva a considerar por qué nuestra pieza aparece en una ofrenda depositada en el basamento del Templo Mayor de México. Es posible que dicho relieve provenga de uno de los pueblos del área Chalco-chinampaneca. La pieza, por ser parte de dicha ofrenda, no puede ser posterior a la época IVa cuando gobernaba Moctezuma I (1440 a 1468 o 1469). Poco antes de 1440 los mexicas habían conquistado Cuitláhuac y la guerra contra Chalco se llevó a cabo de 1446 a 1450, aunque la derrota completa de los chalcas no fue sino hasta 1465. Es factible que este relieve haya sido parte del botín de guerra y se haya incluido en la ofrenda depositada en honor de Huitzilopochtli.

\section{Canto a Atlahua}

Como no poseemos muchos datos sobre Atlahua es importante estudiar el canto a este dios incluido en el Códice Matritense del Real Palacio. Contamos con tres traducciones principales de este canto: la de Eduard Seler, la de Ángel Ma. Garibay y la publicada por Anderson y Dibble ${ }^{28}$ La versión de

\footnotetext{
${ }^{27}$ Henry B. Nicholson, "The Iconography of the Deity Representations in Fray Bernardino de Sahagun's Primeros Memoriales: Huitzilopochtli and Chalchiuhtlicue", The work of Bernardino de Sahagun, Nueva York, University of Albany, 1988a, p. 230.

${ }^{28}$ Eduard Seler, Religious Songs of the Ancient Mexicans, traducción mecanuscrita al inglés, vol 2, parte 4, s.f., p. 81; Ángel María Garibay, Veinte himnos sacros de los nahuas, México, Universidad Nacional Autónoma de México, 1958, p. 211; Apud, Anderson y Dibble, op cit,
} 
estos últimos, en su primera edición del Códice Florentino, es similar a la de Seler pero la traducción en su segunda edición está más apegada a la de Garibay. En estas versiones diferentes se tomaron muy en cuenta las notas marginales al himno de Atlahua ${ }^{29}$ En el apéndice que acompaña a este artículo incluyo las versiones de dicho canto pero quiero referirme aquí a las partes de las traducciones del mismo en las que coinciden los tres estudiosos.

El canto comienza por identificar a Atlahua como chalmécatl, habitante de Chalmecan. Según Garibay "challi significa abertura, pero más en el fondo, borde de una abertura", ${ }^{30}$ dicho de otra manera, es el cerco de tierra que rodea una capa de agua, en este caso las orillas de los lagos de la cuenca de México. Hasso von Winning (comunicación personal) opina que el segundo componente de la palabra chalmécatl es mécatl que puede traducirse como cordel o soga. Es probable que la cuerda que sostiene al máxtlatl de nuestro dios sea una alusión a ello ya que no es usual este tipo de taparrabo ni en los códices ni en las esculturas.

Para reforzar esta alusión hay que agregar que el toponímico de Chalmecan, lugar de los Chalmeca, aparece representado en el Atlas Goupil-Boban mediante una soga que atraviesa un chalchíhuitl. En la lámina 59 de dicho atlas, según nos explica Seler, se encuentra a la izquierda una montaña con cactus y arriba está el dios Huitzilopochtli ataviado como colibrí. En el lado derecho aparecen cuatro personajes que representan a cuatro tribus. El personaje de la parte inferior derecha está acompañado por el toponímico de Chalmecan: un templo arriba del cual hay una soga que pasa a través de un chalchihuitl.."

Torquemada nos informa que la provincia de los Chalmeca se extendía por los llanos y las faldas del Volcán y la Sierra Nevada. ${ }^{32}$ Seler nos dice que dicha provincia no sólo incluía las faldas del Popocatépetl y del Iztaccíhuatl sino también todo el territorio de los lagos de Chalco y Xochimilco; basa esta aseveración en que Gihuacóatl, diosa de Colhuacan, es denominada en

pp. 213-214, y su 2a. edición de 1981; León Portilla, Literatura del México antiguo Los textos en lengua náhuatl, Venezuela, Biblioteca Ayacucho, 1978, publicó la versión de Garibay con algunos pequeños cambios.

${ }^{29}$ Las notas marginales a los cantos son contemporáneos a los mismos pero algunas son más valiosas que otras. Vid., Garibay, op. cit., pp. 20-23.

${ }^{30}$ Ibidem, p. 140. Otra posibilidad es que se derive del chalchihuitl como se verá más adelante.

${ }^{31}$ Eduard Seler, Gesammelte Abhandlungen zur Amerikanischen Sprach-und Alterthumskunde, tomo II, Berlín, 1904, p. 36, fig 3 y p. 45.

32 Juan de Torquemada, Monarquia indiana, vol. 1, México, Universidad Nacional Autónoma de México, 1975, p. 355 
un himno sagrado como chalmecatecutli. ${ }^{33}$ Garibay agrega: "Muchas veces en la documentación, tanto náhuatl como castellana, se habla de los chachalmeca [plural de chalmécatl], bajo el cual nombre se entienden los habitantes de Chalco, Xochimilco, Tláhuac [antiguamente Cuitláhuac], Mixquic, etc." ${ }^{34}$

Posteriormente el canto establece asociaciones entre Atlahua y ciertas prácticas rituales (como la penitencia), con dioses (como Quilaztli y Opochtli) y con elementos (como las cañas, al decir que "la caña es mi flecha"). La mención de las cañas nos indica de nuevo una relación con una comunidad lacustre lo mismo que la referencia a Opochtli, el cual, como ya dijimos anteriormente, era un dios de la pesca y de la caza de animales acuáticos.

Algunos de los veinte himnos sacros recogidos en el Códice Matritense del Real Palacio parecen ser bastante antiguos ya que emplean un lenguaje arcaico desusado en el siglo XVI. ${ }^{35}$ Esto refuerza la creencia de que Atlahua era un dios que ya era venerado por algunos pueblos nahuatlacos de las orillas del lago antes de la llegada de los mexicas.

\section{Estilo del relieve aquí estudiado}

En cuanto al estilo de nuestra pieza muestra ciertas semejanzas con el de los códices del Grupo Borgia como la cabeza grande en proporción al cuerpo y el tipo de nariz grande y carnosa. La forma redonda del ojo no es muy común en dichos códices pero sí aparece. Sin embargo hay ciertas diferencias que no permiten incluir totalmente a nuestra pieza dentro de dicho estilo ya que los miembros del cuerpo están muy abreviados y hay una mayor tendencia al geometrismo por el uso de las líneas rectas. Si se le compara con los relieves mexicas muestra asimismo divergencias ya que la proporción cabeza-cuerpo es distinta (la cabeza es demasiado grande en relación con el cuerpo en nuestro relieve) y además en el arte tenochca se usa más la línea curva. De la actitud dinámica de la figura ya hablé anteriormente en la nota 4.

${ }^{33}$ Eduard Seler, Religious Songs of the Ancient Mexicans, traducción mecanuscrita al inglés, vol 2, parte 4, s.f, p. 82 .

34 Angel María Garibay, Veinte himnos sacros de los nahuas, México, Universidad Nacional Autónoma de México, 1958, p. 140.

${ }^{35}$ Miguel León Portilla, "Religión de los nicaraos", Estudios de cultura náhuatl, vol. 10, México, Universidad Nacional Autónoma de México, 1972, p. 63. 


\section{Conclusiones}

La pieza aquí estudiada puede haber provenido de algún pueblo de las chinampas comprendido dentro de la provincia de los chachalmeca y quizá fue traída a Tenochtitlan como botín de guerra. Como el dios labrado en ella es Atlahua la pieza puede ser originaria de Cuitláhuac donde esta deidad era venerada según nos dicen las fuentes. La importancia del relieve radica en que es la única imagen de esta divinidad labrada en piedra encontrada o identificada hasta este momento ya que las otras figuras de Atlahua aparecen en el Códice Borbónico, en el Códice Matritense del Real Palacio y en el Códice Florentino. ${ }^{36}$

Apéndice con las traducciones del Canto a Atlahua.

\section{Versión de Seler.}

\section{The Song of the God of Cuitlahuac}

I, the man from the Chalman country, I, the man from the Chalman country. The abandoned fasts, the abandoned fasts.

The disk (the frontal shield), the head device.

They pine-branch

Quilazteotl, the old (goddess), thy pine-branch.

I call thee the "lord of the reed"

thou usest the shield, in order to draw blood from thyself

I call thee the "lord of the reed".

That I carry no arrow, is my boast, when it is said, the reed is my arrow, the cleft reed is my boast.

In the Teteoman (temple) the priest Teteometl has become active (has been born),

He is now a quetzal bird, I nourished him (with offerings).

${ }^{36}$ Agradezco al doctor Hasso von Winning sus valiosos comentarios a este artículo y además la realización de los dibujos que lo acompañan. 


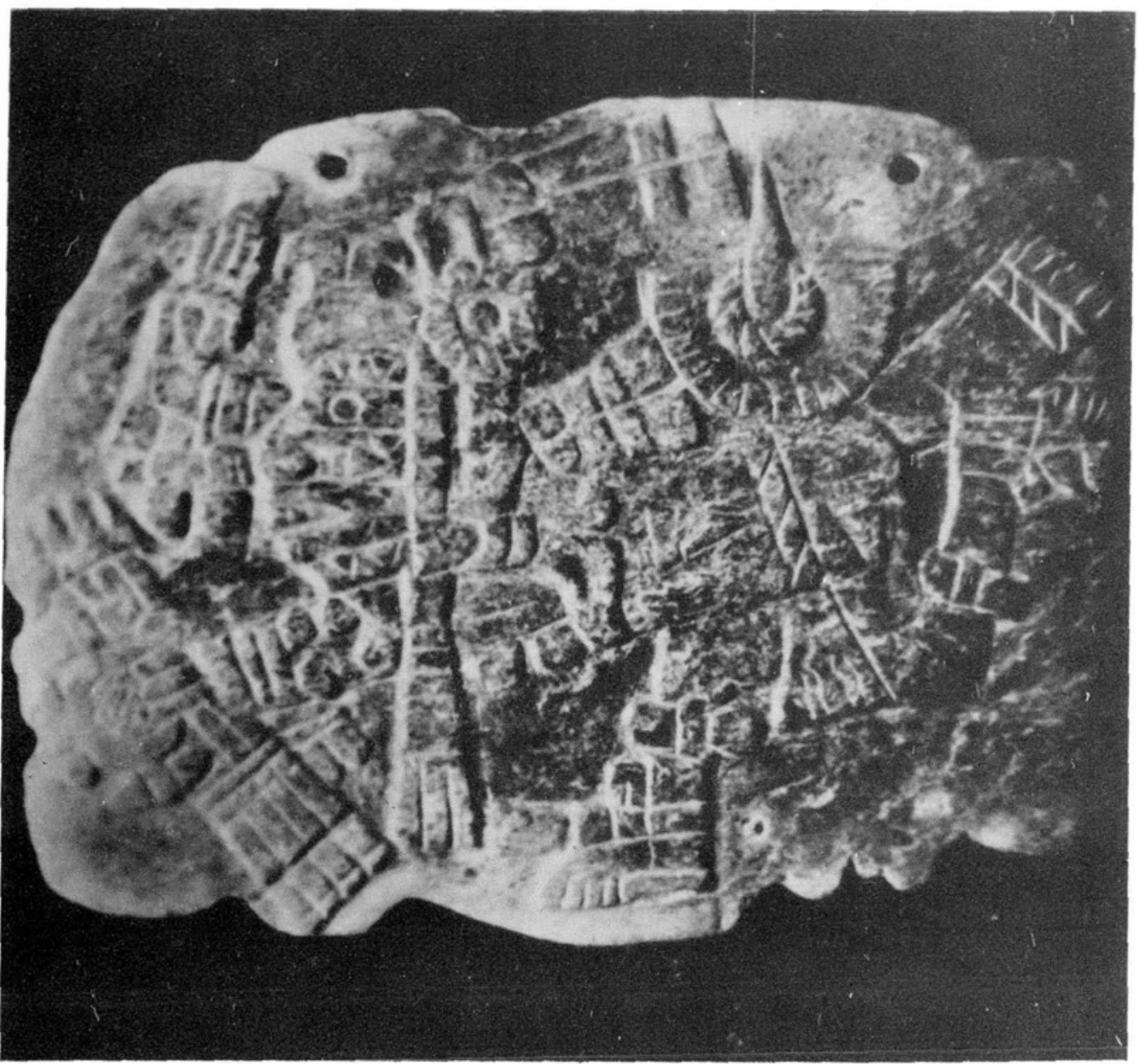

1. Pectoral con el dios Atlahua. Foto cortesía del Instituto de Investigaciones Estéticas, UNAM. 


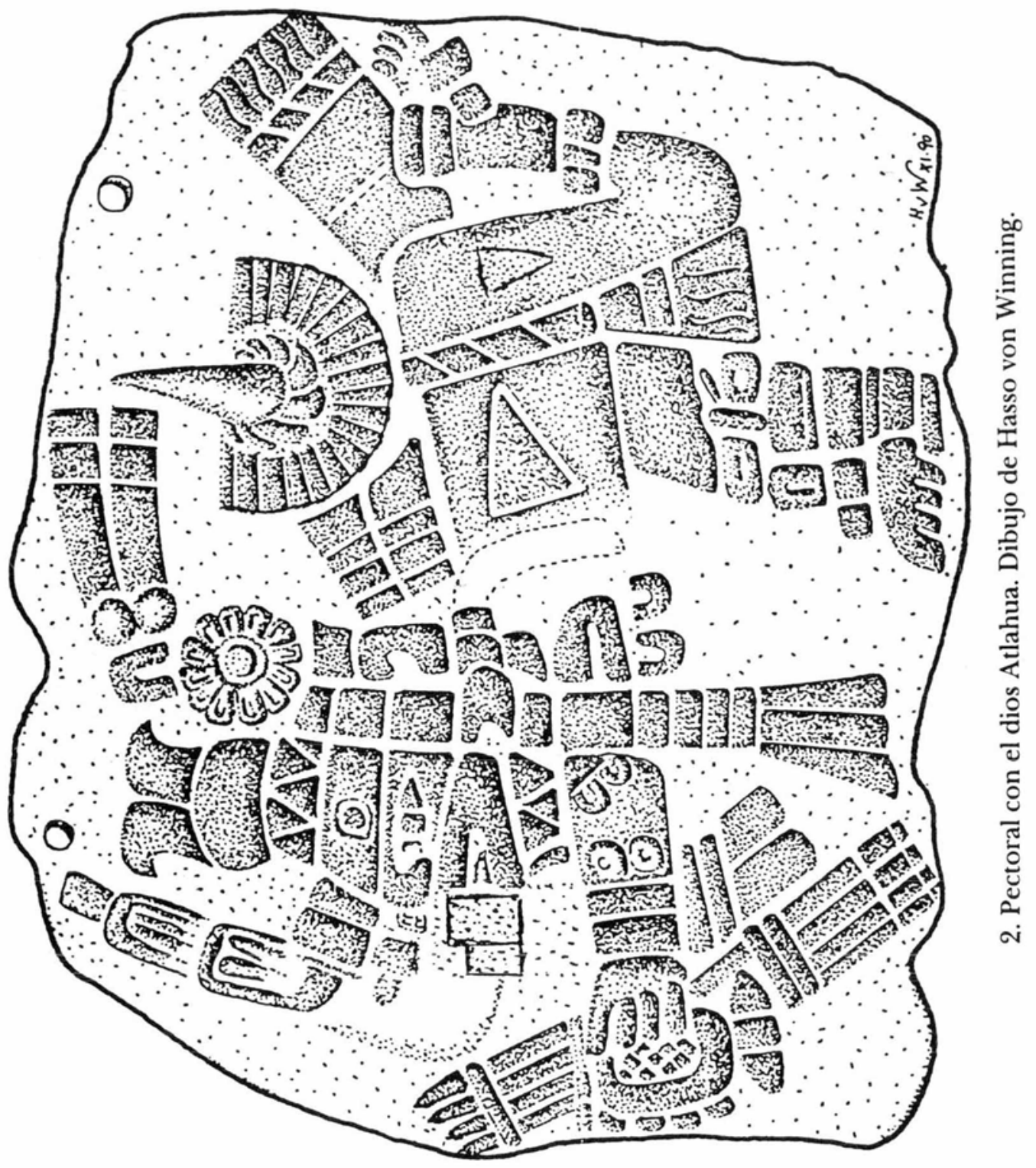




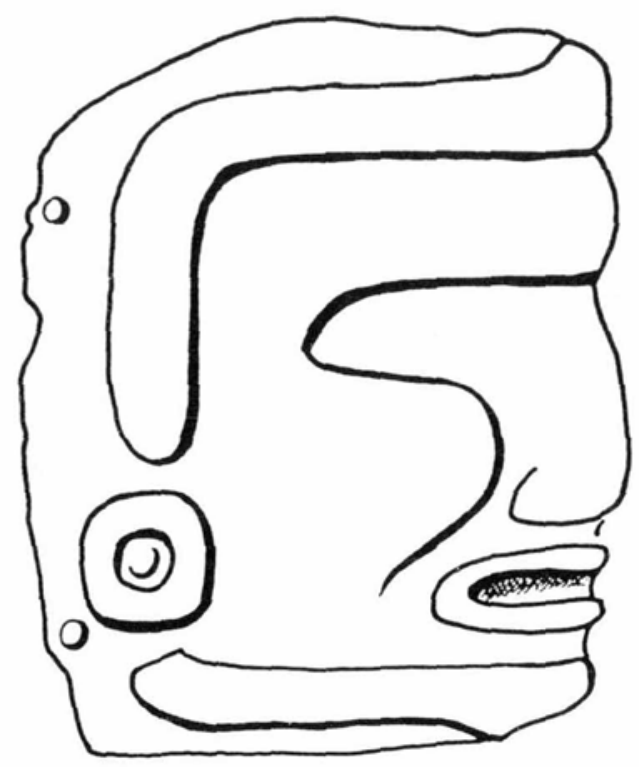

3. El rostro humano del otro lado del pectoral. Dibujo de Hasso von Winning.

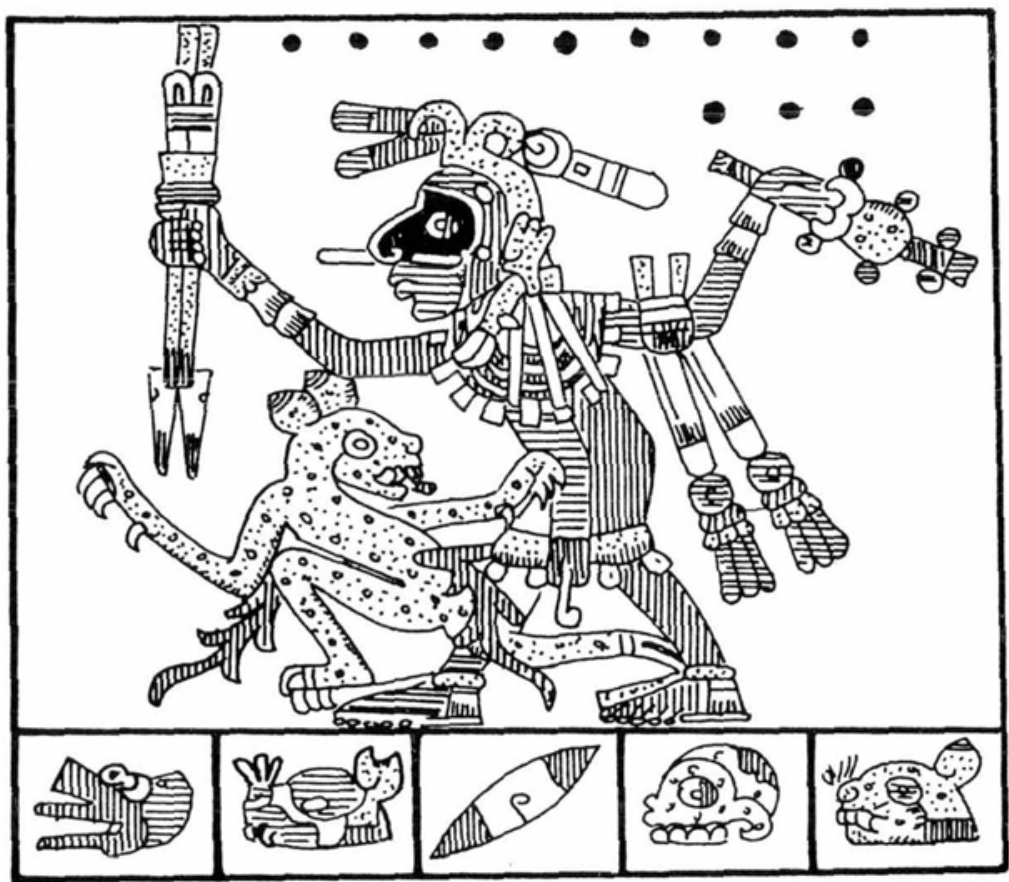

4. Mixcóatl, página 41 del Códice Fejérváry-Mayer. Dibujo de Hasso von Winning. 

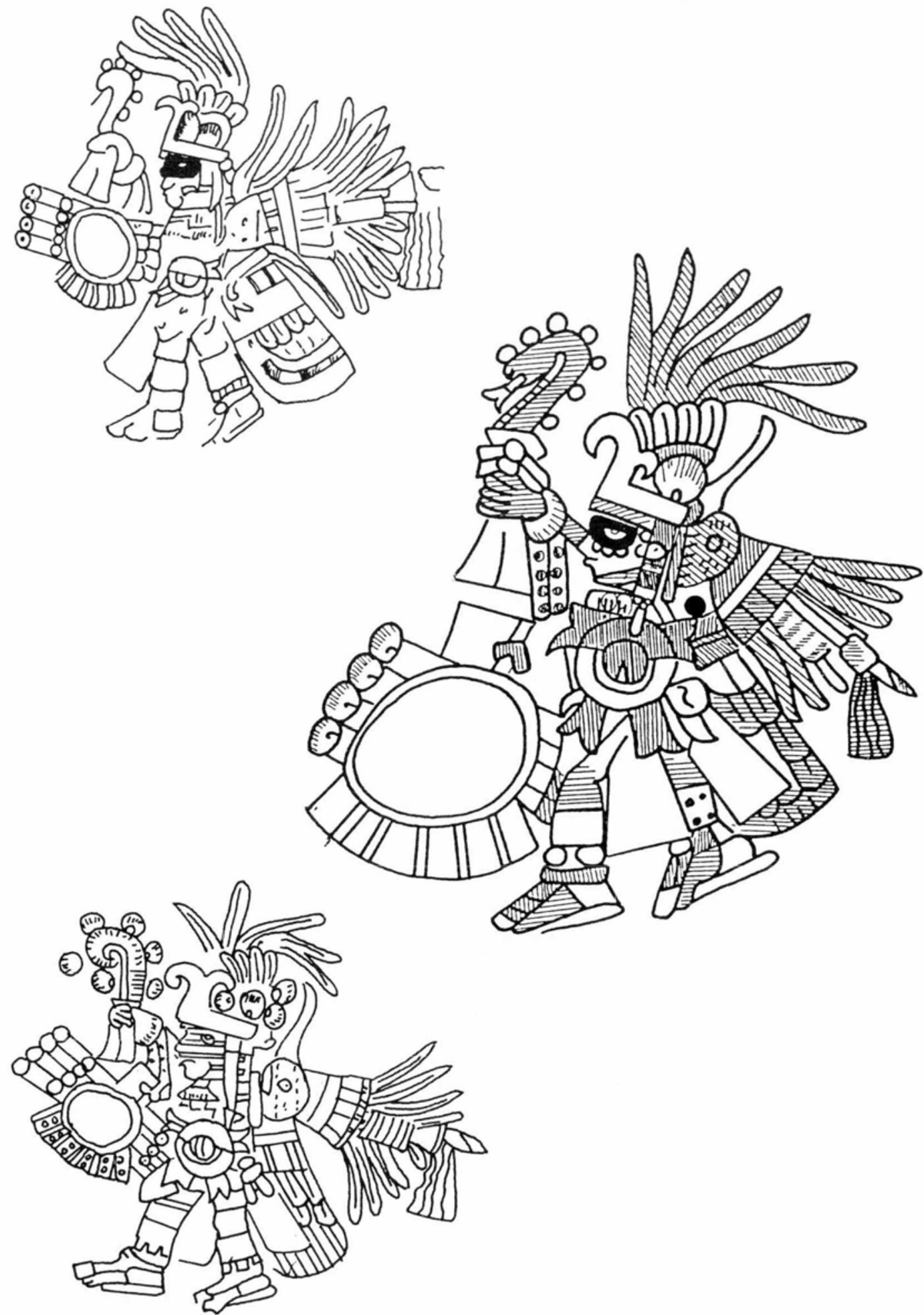

5. abc Huitzilopochtli, láminas 31, 34 y 36 del Códice Borbónico. Dibujos de Hasso von Winning. 


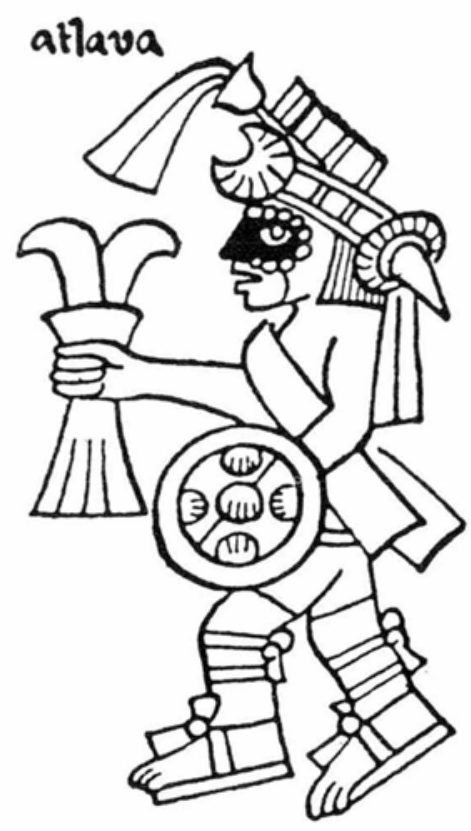

6. Atlahua, Códice Matritense del Real Palacio, fol. 265 r. (dibujo tomado de León-Portilla, 1958).

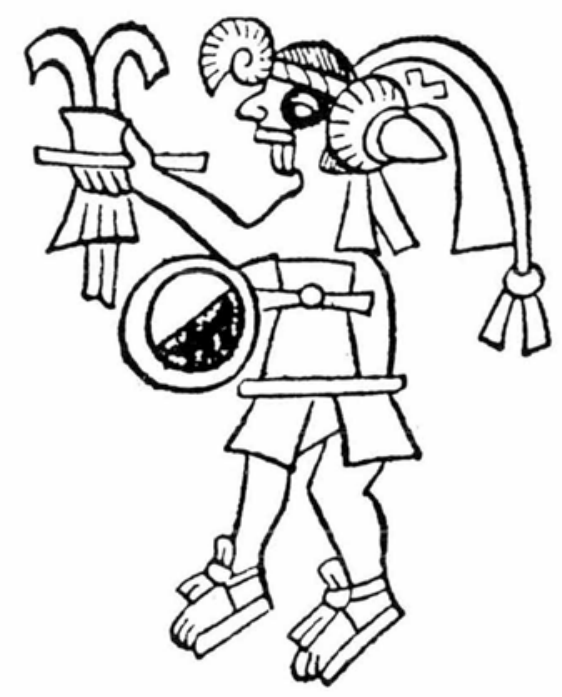

7. Uno de los dioses de Chalman, Códice Matritense del Real Palacio, fol. 262 r. (dibujo tomado de León-Portilla, 1958). 

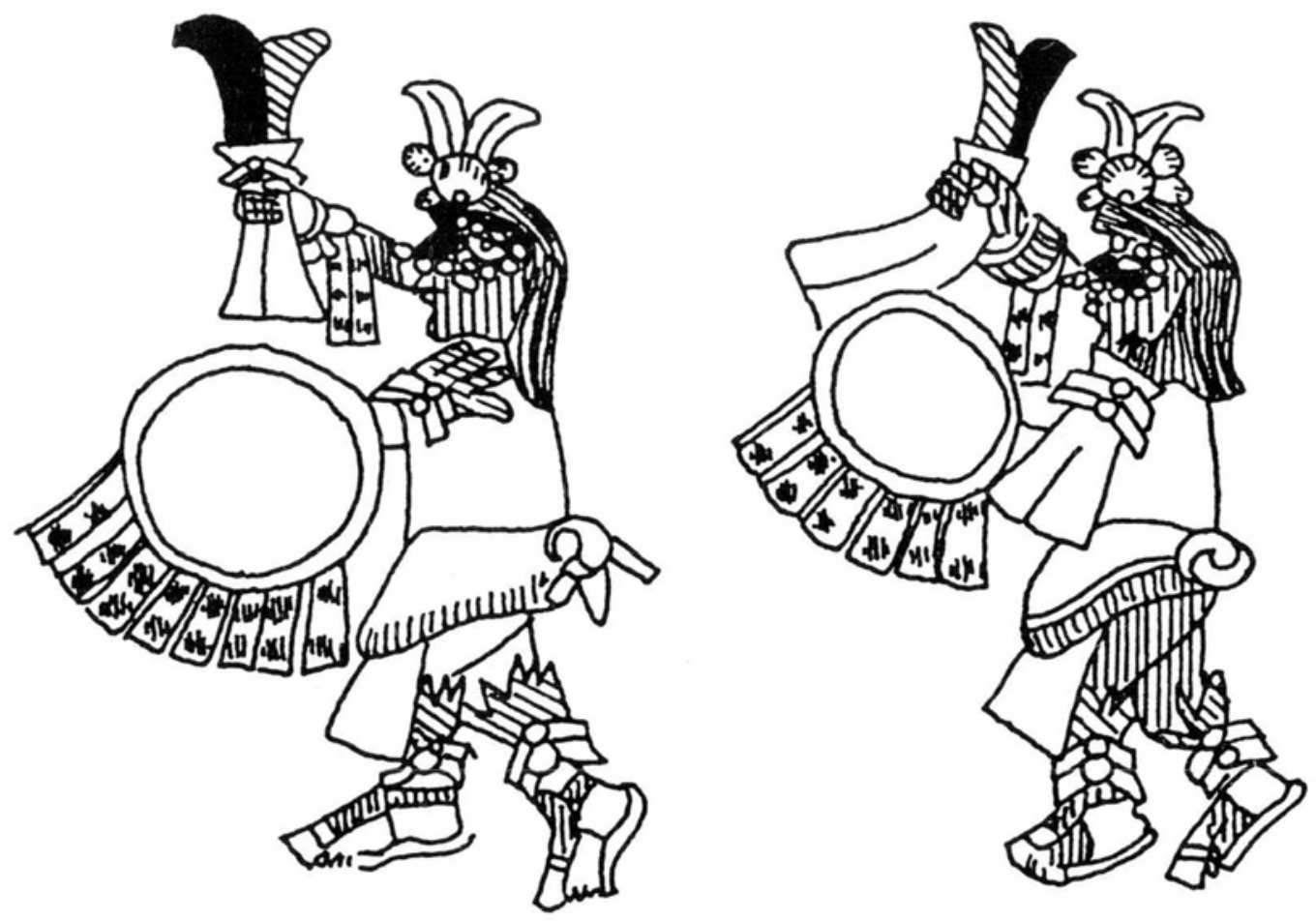

8. Atlahua en el Códice Borbónico, láminas 26 y 28. Dibujo de Hasso von Winning. 
DOI: http://dx.doi.org/10.22201/iie.18703062e.1992.63.1642

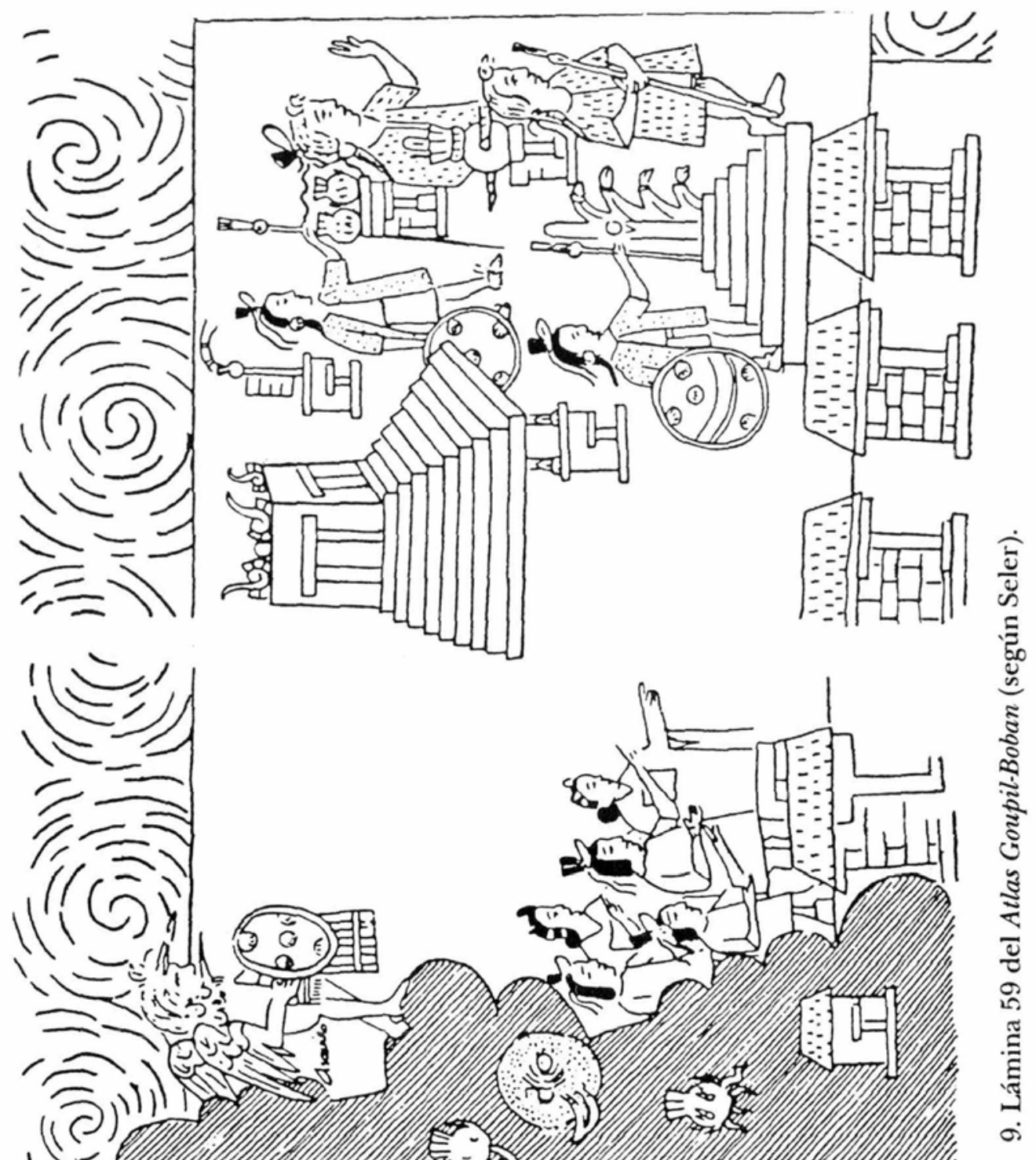




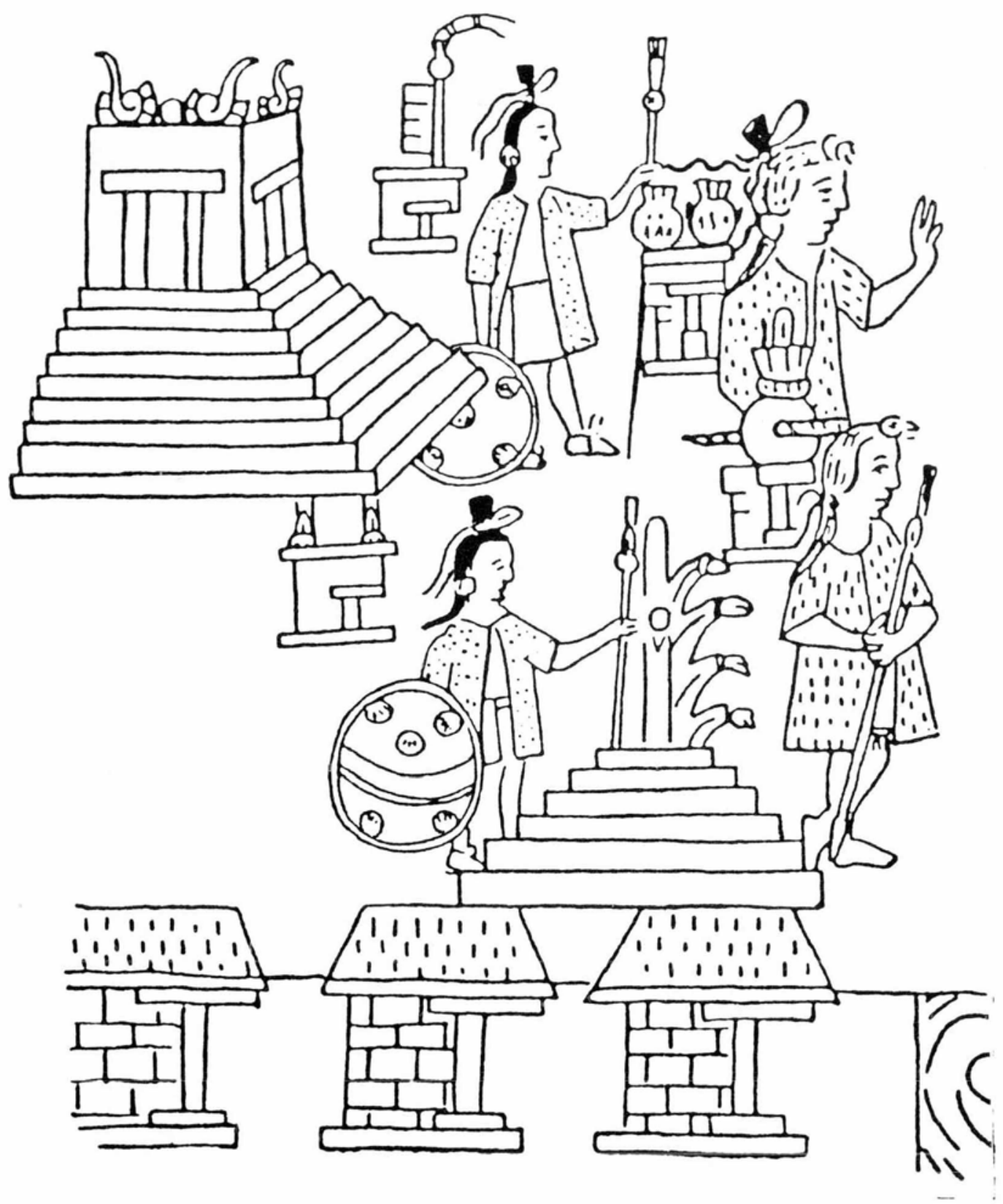

10. Detalle de la lámina 59 del Atlas Goupil-Boban (según Seler). 
Opochtli, my god, Atlahua, and now is he a quetzal bird

I nourished him (with offerigns), ${ }^{37}$

Versión de Ángel Ma. Garibay con pequeños cambios hechos por Miguel León Portilla.

\section{Canto de Atlahua}

-Yo soy el de Chalman, yo soy el de Chalman, el de las sandalias de penitente, el de las sandalias de penitente: oscila el sol de mi frente, oscila.

-Grande, grande es tu manojo de abeto: es la escoba de la diosa Quilaztli: tu manojo de abeto.

-Yo a ti, cual a Señor de las cañas clamo, al que se sangra sobre su escudo:

-Yo a ti, cual a Señor de las cañas clamo

-No tengo flecha: de orgullo es su historia.

Caña es mi flecha, se esparcen las cañas.

De orgullo es su historia.

-En Tetoman es tu vivencia, oh Proveedor de Tetoman.

-No sin esfuerzo, al Ave Quetzal yo debo alimentar.

Opochtli es mi dios, el Dueño de las aguas.

No sin esfuerzo, al Ave Quetzal yo debo alimentar. ${ }^{38}$

Versión de Anderson y Dibble en su primera edición al Códice Florentino. El nombre del dios lo escriben sin $\mathrm{h}$.

\section{Song of Atlauä}

I am he from Chalman. I am he from Chalmanthe broken fast, the disc head device.

[I am] the branch of fir Quilazteotl; [I am] the old goddess, the branch of fir.

${ }^{37}$ Eduard Seler, op cit., p. 81.

${ }^{38}$ Miguel León Portilla, Literatura del México antiguo. Los textos en lengua náhuatl, Venezuela, Biblioteca Ayacucho, 1978, p. 103. 
I name thee lord of reeds. On the shield is blood drawn. I am thee lord of reeds.

That none are my arrows is my boast. The reed is my arrow; the hollow reed is my boast.

In Tetoman the priest Tetometl began life. Now he is a quetzal bird, that I may nourish him.

Opochtli is my god, Atlaua that I may nourish him. ${ }^{39}$

\section{Segunda versión.}

I am the man from Chalman

I am the man from Chalman

With penance sandals

With forehead sun-jewel

Which trembles

It trembles

Big

Big is your fir branch

The broom of Quilaztli

Your branch of a fir tree

I call to you

Lord of the reeds

Over your shield

Blood is being shed

I call to you

Lord of the reeds

My darts are gone

Pround is their tale

Reeds are my darts

None break in two

Proud [is their tale]

Tetoman is where you abide

Maker of gifts in Tetoman

Not with ease

Do I nourish

the quetzal bird

Opochtli is my god

The one with dart throwers

${ }^{39}$ Apud, Anderson y Dibble, Florentine Codex, 2a ed, Nuevo México, 1981, pp 213, 214 
[Not with ease]

Do I nourish

[The quetzal bird $]^{40}$

\section{BIBLIOGRAFÍA}

Anales de Cuauhtitlan - ver Códice Chimalpopoca.

Anderson, Arthur J.O.: y Charles E. Dibble - ver Sahagún, Códice Florentino.

Brundage, Burr C.: El Quinto Sol. Dioses y mundo azteca, México, Diana, 1982.

Codex Cospi, Codices Selecti, vol. XVIII, Graz, Austria, Akademische Druck-u Verlagsanstalt, 1968.

Codex Fejéruáry-Mayer, Codices Selecti, vol. XXVI, Graz, Austria, Akademische Druck-u Verlagsanstailt, 1971.

Codex Magliabechiano, Edición de Elizabeth H. Boone, Berkeley, University of California Press, 1983

Codex Vaticanus 3773, Codices Selecti, vol. XXXI, Graz, Austria, Akademische Druck-u Verlagsanstalt, 1975.

Códice Borbónico, México, Siglo Xxı, 1979.

Códice Borgia - ver Seler, E

Códice Chimalpopoca, Anales de Cuauhtitlan y Leyenda de los Soles, traducción de P.F. Velázquez, México, Universidad Nacional Autónoma de México, 1975.

Códice Laud, Antigüedades de México basadas en la recopilación de Lord Kingsborough, vol. 3, México, 1964.

Códice Mendocino, Antiguedades de México basadas en la recopilación de Lord Kingsborough, vol. 1, México, 1964.

Códice Telleriano-Remensis, Antigüedades de México basadas en la recopilación de Lord Kingsborough, vol. 3, México, 1964.

Códice Vaticano A, Antigüedades de México basadas en la recopilación de Lord Kingsborough, vol. 3, México, 1964.

Códices Matritenses de la Historia General de las Cosas de la Nueva España, Colección Chimalistac, vols. 19 y 20, México, Edit. Porrúa, 1964.

Chimalpahin, Domingo: Octava Relación, Edición y versión castellana de José Rubén Romero, México, Universidad Nacional Autónoma de México, 1983.

Davies, Niguel: Los mexicas. Primeros pasos hacia el Imperio, México, Universidad Nacional Autónoma de México, $1973 a$.

The Aztecs, Londres, Macmillan, 1973b.

Durand-Forest, Jacqueline de: "Los grupos chalcas y sus divinidades según Chimalpahin", Estudios de Cultura Náhuatl, vol. 11, pp. 37-44, México, Universidad Nacional Autónoma de México, 1974.

${ }^{40}$ Apud, Anderson y Dibble, op. cit. p. 243 
García Cook, Ángel, y Raúl M Arana: Rescate arqueológico del monolito Coyolxauqui, México, Instituto Nacional de Antropología e Historia, 1978.

Garibay, Ángel Ma:: Veinte himnos sacros de los nahuas, México, Universidad Nacional Autónoma de México, 1958.

González-Blanco, Salomón: Tláhuac prehispánico, México, Edit. Miguel Ángel Porúa, México, 1988.

"Historia de los mexicanos por sus pinturas", en Teogonia e historia de los mexicanos, edición de Ángel Ma. Garibay, México, Edit. Porrúa, 1965.

Jiménez Moreno, Wigberto: Primeros memoriales de Fray Bernardino de Sahagún, México, Instituto Nacional de Antropología e Historia, 1974.

León Portilla, Miguel: Ritos, sacerdotes y atavios de los dioses, México, Universidad Nacional Autónoma de México, 1958.

___ "Religión de los nicaraos", Estudios de Cultura Náhuatl, vol. 10, México, Universidad Nacional Autónoma de México, 1972.

- Literatura del México antiguo, Los textos en lengua náhuatl, Venezuela, Biblioteca Ayacucho, 1978.

López Austin, Alfredo: "Iconografía mexica, el monolito verde del Templo Mayor", Anales de Antropologia, núm. XVI (México, 1979), pp. 133-153.

_ Nota sobre la fusión y la fisión de los dioses en el panteón mexica", Anales de Antropologia, vol 1, núm. XX (México, 1983).

Matos, Eduardo: "The Templo Mayor of Tenochtitlan, History and Interpretation". The Great Temple of Tenochtitlan, pp. 15-60, University of California Press, Berkely, 1987.

— "Imperial Tenochtitlan", Mexico Splendors of Thirty Centuries, Nueva York, The Metropolitan Museum of Art, 1990.

Nicholson, Henry B : Religion in Pre-Hispanic Central Mexico, Handbook of Middle American Indians, vol. 10, Austin, University of Texas Press, 1971.

"Sahagun's 'Primeros Memoriales', Tepepulco", Handbook of Middle American Indians, vol. 13, Austin, University of Texas Press, 1973.

"The Iconography of the Deity Representations in Fray Bernardino de Sahagun's Primeros Memoriales: Huitzilopochtli and Chalchiuhtlicue", The Work of Bernardino de Sahagun, Nueva York, University of Albany, 1988a.

"The Provenience of the Codex Borbonicus: An Hypothesis", Smoke and Mist, England, BAR International Series 402 (1), 1988b.

Sahagún, Bernardino de: Florentine Codex, traducción al inglés, edición y notas de Arthur J O. Anderson y Charles E. Dibble, Nuevo México, 1951-1975; segunda edición, 1981.

- Historia general de las cosas de Nueva España, edición de Ángel María Garibay, México, Edit Porrúa, 1956.

Seler, Eduard: Ein Kapitel aus den Geschichtswerk des P. Sahagun, vol. 1, Cuaderno 4, Berlín, 1890.

- Gesammelle Abhandlungen zur Amerikanischen Sprach-und Alterthumskunde, tomo II, Berlín, 1904 
DOI: http://dx.doi.org/10.22201/iie.18703062e.1992.63.1642

_ Comentarios al Códice Borgia, México, Fondo de Cultura Económica, 1963.

Religious Songs of the Ancient Mexicans, traducción mecanuscrita al inglés, vol. 2, parte 4, s.f.

Tyonalámatl de Aubin, Estudio introductorio de Carmen Aguilera, México, Gobierno del Estado de Tlaxcala, 1981.

Torquemada, Juan de: Monarquía Indiana, vols. 1 y 3, México, Universidad Nacional Autónoma de México, 1975-1976. 